\title{
NOVEL KARTINI KISAH YANG TERSEMBUNYI KAYA AGUK IRAWAN MN ANALISIS FEMINISME LIBERAL
}

\author{
Andriani Sandi Fransiska \\ (Program Studi Pendidikan Bahasa dan Sastra Indonesia, Fakultas Keguruan dan Ilmu \\ PendidikanUniversitas PGRI Adi Buana Surabaya) \\ andrianifransiska17@gmail.com \\ Luluk Isani Kulup \\ (Program Studi Pendidikan Bahasa dan Sastra Indonesia, Fakultas Keguruan dan Ilmu \\ PendidikanUniversitas PGRI Adi Buana Surabaya) \\ kulupluluk@gmail.com
}

\begin{abstract}
"Novel Kartini" The Hidden Story is the work of Aguk Irawan MN.Novel which describes the life of a woman who demands her right to be equal with men. Kartini's character is an independent female figure who wants to gain the struggle to get education, liberate women from injustice or discrimination to obtain education, and indigenous discrimination that gives rise to injustice for women. Kartini is a Javanese woman born of a common woman. But Kartini has a high spirit spirit in order to get a good education for himself and his people. Kartini also has the spirit to become teachers, doctors, and midwives in order to educate their people and help deliver the mother who gave birth to her baby could be saved. But, Kartini's fate is so bad. Until Kartini 25 years old Kartini married degan man who is paired by his father with his royal friend and at that age also Kartini has died. Kartini at that time also known as pioneer of indigenous revival which with spirit high writing letters to his best friend that he wanted to rebel so that women's lives can be synchronized with men in general.
\end{abstract}

Keywords: Emansipasid in Kartini Novel, Liberal Feminism

\section{PENDAHULUAN}

Karya sastra merupakan
sarana yang digunakan oleh pengarang untuk mengungkapkan perasaan, ide, dan segala permasalahan hidup dari kehidupan manusia. Pengungkapan itu akan terealisasi apabila ada pengalaman yang dialami sendiri oleh pengarang atau melihat realita yang ada pada masyarakat. Segala pengalaman hidup dan kehidupan itu menjadi objek penciptaan karya sastra, pengarang hendaknya menerima kenyataa yang ada disekitarnya yang dituangkan dalam sebuah karya sastra.

Sastra adalah suatu kegiatan kreatif, sebuah karya seni. Studi sastra memiliki metode-metode yang ilmiah, walau tidak selalu sama dengan metode-metode ilmu-ilmu alam. Bedanya hanya saja ilmu-ilmu alam berbeda dengan tujuan ilmuilmu budaya.Dengan demikian, sastra berarti alat untuk mengajar atau buku petunujuk atau bukti intruksi atau buku pengajaran.Di samping kata sastra, kerap juga disebut susastra, yang berarti bahasa yang indah awalan su pada kata susastra mengacu pada arti indah.

Sastra adalah ungkapan spontan dari perasaan yang mendalam.Sastra juga merupakan ekspresi pikiran dalam bahasa, pandangan, ide-ide, perasaan, pemikiran dan semua 
kegiatan mental manusia, dan juga keterlibatan individu dalam kehidupan bermasyarakat Rafiek (2010:24).Partisipasi wanita dianggap tidak diperlukan, kaum laki-laki selalu mendominasi dalam ranah apapun.Dominasi lelaki serta sistem patriarki serta melakukan sesuatu tindakan untuk menentangnya, adalah seorang feminisme.

Tokoh aliran ini adalah Naomi Wolf, sebagai "Feminisme Kekuatan" yang merupakan solusi.Kini perempuan telah mempunyai kekuatan dari segi pendidikan dan pendapatan, dan perempuan harus terus menuntut persamaan haknya serta saatnya kini perempuan bebas berkehendak tanpa tergantung pada lelaki.Akar teori ini bertumpu pada kebebasan dan kesetaraaan rasionalitas.Perempuan adalah makhluk rasional, kemampuannya sama dengan laki-laki, sehingga harus diberi hak yang sama juga dengan laki-laki. Permasalahannya terletak pada produk kebijakan negara yang bias gender.

Feminisme berkembang menjadi beberapa bagian seperti feminisme liberal, feminisme radikal, feminisme anarkis, feminisme sosialis, feminisme postkolonial, feminisme postmodern, feminisme sosialis. Menggambarkan pemikiran feminisme liberal, ditegaskan sebagai pemikiran yang "berkomitmen kepada pengaturan ulang ekonomi secara besar-besaran, dan retribusi kemakmuran secara signifikan, karena salah satu dari tujuan politik modern yang paling dekat dengan feminisme liberal adalah kesetaraan kesempatan, yang tentu saja akan menuntut dan juga membawa kepada kedua komitmen tersebut.

\section{METODE PENELITIAN}

Penelitian ini termasuk jenis penelitian kualitatif dengan metode analisis deskriptif. Menurut Bogdan dan Taylor dalam Moleong (2010:4) pendekatan kualitatif adalah konsepkonsep dan keterangan yang berbentuk uraian dalam mengungkap masalah.Penelitian kualitatif adalah sebagai prosedur penelitian yang menghasilkan data.Sedangkan metode deskriptif yaitu berupa kata-kata tertulis atau lisan dari orang-orang dan perilaku yang dapat diamati Ratna (2012:53). Data-data formal diambil dari novel Kartini Kisah yang Tersembunyi karya Aguk Irawan MN Analisis Feminisme Liberal yang diterbitkan pada tahun 2016.

Hal ini sesuai dengan yang dikemukakan oleh Ratna (2012:47), bahwa pendekatan kualitatif memberikan perhatian terhadap data alamiah yaitu data dalam hubungannya dengan konteks keberadaannya.Objek penelitian bukan gejala sosial sebagai bentuk substantif melainkan makna-makna yang terkandung dibalik tindakan yang justru mendorong timbulnya gejala sosial tersebut. Dalam hubungan inilah pendekatan kualitatif dianggap sama dengan pemahaman. sesuai dengan namanya, pendekatan ini mempertahankan nilai-nilai sehingga pendekatan ini dipertentangkan dengan pendekatan kualitatif yang berarti bebas nilai.

\section{HASIL PENELITIAN DAN PEMBAHASAN}

Pada novel Kartini Kisah yang Tersembunyi karya AgukIrawan MN terdapat beberapa poin yaitu dari Segi Politik, Segi Sosial, dan Segi Ekonomi yang berlandaskan pada teori Naomi Wolf yang berartikan Feminise Kekuatan dan didalamnya 
berisiperempuan tidak hanya harus berjuang menentang diskriminasi, tetapi juga berjuang demi emansipasi serta pembebasan dari segenap bentuk penindasan dari kaum laki-laki. Dan ingin menjunjung martabat dari perempuat atas ketidaksetaraan dengan kaum laki-laki.

\section{Segi Politik}

Politik sendiri merupakan pengambilan keputusan melalui sarana umum dan mendefinisikan politik sebagai berbagai macam kegiatan yang terjadi di suatu Negara yang menyangkut proses mennentukan tujuan dan berbagai cara mencapai tujuan.

"Ini kisah Kartini, kisah tentang hati dan pikirannya, yang akan menampakkansecara nyata dan terang benderang bahwa sesungguhnya kehidupan Kartini adalah kehidupan cinta yang sederhana, sebagaimana watak cinta itu sendiri”.

$\begin{array}{lr}\text { "Dengan } & \text { cinta, } \\ \text { bersenandunglah } & \\ \text { jiwanya.Tentang } & \text { kaum } \\ \text { perempuan, tentangkemiskinan, } \\ \text { tentang penderitaan, tentang } \\ \text { adat, tentang bangsa Eropa, dan } \\ \text { tentang cita-citanya terhadap } \\ \text { Bumi putra.Dengan cinta, } \\ \text { bernapaslah ia dengan napas } \\ \text { rakyat dan bangsanya". }\end{array}$

Dari kutipan di atas nilai politik terdapat dalam kutipan "Tentang kaum perempuan, tentang kemiskinan, tentang penderitaan, tentang adat, tentang bangsa Eropa, dan tentang cita-citanya terhadap Bumi putra.Dengan cinta, bernapaslah ia dengan nafas rakyat dan bangsanya". bahwa Kartini ingin memperlihatkan atau menampakkan dengan nyata bahwa kehidupan Kartini yang sebenarnya adalah kehidupan cinta yang sederhana dan sebagaiamana yang Kartini lakukan terhadap sesama kaum perempuannya dan dengan ketulusan cinta Kartini tentang kaum perempuan dengan kemiskinan, tentang penderitaan, tentang adat, tentang bangsa Eropa, dan tentang cita-citanya terhadap Bumi putra. Dan berjuanglah Kartini untuk menyetarakan antara kaum lakilaki dan perempuan agar penindasan terhadap kaum perempuan tidak terus terjadi.

\section{Segi Sosial}

Sosial merupakan nilai yang mendasari, menuntun dan menjadi tujuan tindakan dan hidup sosial manusia dalam melangsungkan,mempertahankan dan mengembangkan hidup sosial manusia dan tingkah laku, interaksi, ide, gagasan, dan struktur masyarakat.Pada novel Kartini Kisah yang Tersembunyi karya Aguk Irawan MN mengandung politik.

"Memang, ia tahu bahwa tak mungkin ia bisa menolak kemauan Sosroningrat. Penolakan terhadap seorang priyayi, baginya juga umumnya bagi rakyat jelata Jawa tak hanya bisa melukai perasaan sang priyayi". "Sebab "Tuhan berbicara melalui lidah bangsawan".Sabda Pandita Ratu. Menentang keinginan "raja kecil" sama artinya menentang keinginan Tuhan. Dan menentang keinginan 
Tuhan sama artinya dengan bencana".

Dari kutipan di atas nilai sosial ada pada kutipan "Memang, ia tahu bahwa tak mungkin ia bisa menolak

Sosroningrat".Menjelaskan bawha perilaku rakyat jelata tidak bakalan bisa menolak keinginan seorang priyayi seperti Sosroningrat.Dan "Menentang keinginan "raja kecil" sama artinya menentang keinginan Tuhan".Bahwa anak raja atau raja kecil kalau dia meninginkan sesuatu harus dituruti dalam waktu itu.

\section{Segi Ekonomi}

Ekonomi merupakan satu kajian ilmu yang berhubungan tentang sumber daya material individu dan masyarakat serta negara untuk meningkatkan kesejahteraan manusia sehingga ekonomi menjadi satu diantara ilmu yang terkait tentang tingkah laku dan aksi manusia dalam memenuhi kebutuhan hidupnya yang berkembang dengan adanya ssumber daya melalui kegiatan mengonsumsi, distribusi, dan produksi.

"Tidak mengherankan apabila Sultan Hamengkubuwana ke VII memperoleh julukan sebagai Sultan Sugih. Bayangkan, kesugihan di tengah-tengah rakyat jelata yang tercekik kemiskinan dan tenggelam dalam air mata kepedihan".

Dari kutipan di atas nilai ekonomi ada pada kutipan "memperoleh julukan sebagai
Sultan Sugih".Menjelaskan bahwa Sultan Hamengkubuwana sangatlah kaya sampai-sampai rakyat jelata tercekik kemisikinan.

Feminisme berasal dari bahasa Latin, femina atau perempuan.Istilah ini mulai digunakan pada tahun 1890an, mengacu pada teori kesetaraan laki-laki dan perempuan serta pergerakan untuk memperoleh hakhak perempuan.ada beberapa macam feminisme yang pertama feminisme liberal ialah teori tentang persamaan antara laki-laki dan perempuan di bidang politik, sosial, ekonomi, atau kegiatan terorganisasi yang memperjuangkan hak-hak serta kepentingan perempuan menurut Goefe dalam Sugihastuti (2010:18).

Feminisme Liberal ialah terdapat pandangan untuk menempatkan perempuan yang memiliki kebebasan secara penuh dan individual.Aliran ini bertumpu pada Naomi Wolf yang sosial, politik, ekonomi.Dari segi sosial ialah tingkah laku, interaksi, ide, dan struktur masyarakat.Ekonomi ialah memenuhi kebutuhan kehidupan seperti distribusi dan konsumsi masyarakat. Politik ialah hak wewenang, kekuasaan, proses pengambilan keputusan dan konflik yang terjadi didalam masyarakat.

Feminisme liberal mempunyai pandangan bahwa perempuan memiliki kebebasan secara penuh dan individual.Ragam ini menyatakan bahwa kebebasan dan kesamaan berakar pada rasionalitas dan pemisahan antara dunia privat dan publik.Setiap manusia punya kapasitas untuk berpikir dan bertindak secara rasional, begitu pula pada perempuan.akar ketertindasan dan keterbelakangan pada perempuan 
ialah disebabkan oleh kesalahan perempuan itu sendiri. Perempuan harus mempersiapkan diri mereka agar dapat bersaing dan punya kedudukan setara dengan lelaki Humm dalam Sugihastuti (2010:181)

Feminisme Radikal ialah pemahaman penindasan laki-laki terhadap perempuan adalah satu fakta dalam system masyarakat yang sekarang ada.Dan gerakan ini adalah radikal.Aliran ini bertumpu pada pandangan bahwa penindasan terhadapa perempuan terjadi akibat system patriarki.Tubuh perempuan merupakan objek utama penindasan oleh kekuasaan laki-laki.Oleh karena itu feminisme radikal mempermasalahkan antara lain tubuh serta hak-hak reproduksi, seksualitas (termsuk lesbianisme), seksisme, relasi kuasa perempuan dan laki-laki dan dikotomi privat publik (Wikipedia). Feminisme Post modern ialah ide yang anti absolut dan anti otoritas, gagalnya modernitas dan pemilihan secara berbeda-beda tiap fenomena sosial karena penentangannya dan penguniversalan pengetahuan ilmiah dan sejarah, mereka nerpendapat bahwa gender tidak bermakna identitas atau struktur sosial. Feminisme anarkis ialah feminisme yang pahma, akan politik yang mencita-citakan masyarakat sosialis dan menganggap negara dan system patriarki dominasi lelaki dan sumber permasalahan yang sesegera mungkin harus dihancurkan. Feminisme Marxis ialah negara bersifat kapitalis yakni menganggap bahwa negara bukan hanya sekedar institusi tetapi juga perwujudan dari interaksi atau hubungan sosial. Kaum marxis berpendapat bahwa negara memiliki kemampuan untuk memelihara kesejahteraan, namun disisi lain negara bersifat kapitalisme yang menggunakan system perbudakan kaum wanita sebagai pekerja. Feminisme Sosialis ialah tak ada sosialisme tanpa pembebasan perempuan.tak ada pembebasan perempuan tanpa sosialisme, feminisme sosialis berjuang untuk menghapuskan pemilikan. Lembaga perkawinan yang melegalisir pemilikan pria atas istri dihapuskan seperti ide Marx yang menginginkan suatu masyarakat tanpa kelas, tanpa pembedaan gender.

Emansipasi adalah istilah yang digunakan untuk menjelaskan sejumlah usaha untuk mendapatkan hak politik maupun persamaan derajat, sering bagi kelompok yang tak diberi hak secara spesifik, atau secara lebih umum dalam pembahasan masalah seperti itu.Khamdiyah (2016:1) Emansipasi wanita adalah sebuah pergerakan kolektif yang bertujuan untuk mendefinisikan, membangun, dan mempertahankan hak-hak politik, ekonomi, dan sosial yang setara bagi wanita.Sebagai tambahan, feminisme juga mencari dan menegakkan kesempatan wanita dalam pendidikan dan pekerjaan yang setara.Kasir (2016:19) Emansipasi wanita adalah sebuah pergerakan kolektif yang bertujuan untuk mendefinisikan, membangun, dan mempertahankan hak-hak politik, ekonomi, dan sosial yang setara bagi wanita.Sebagai tambahan, feminisme juga mencari dan menegakkan kesempatan wanita dalam pendidikan dan pekerjaan yang setara Emansipasi wanita bertujuan memberi wanita kesempatan bekerja, belajar, dan berkarya seperti halnya pria, seimbang dengan kemampuannya. Pengertian sama di sini lebih dipersepsikan pada kata sejajar karena tidak bisa dipungkiri 
wanita dan laki-laki jelas-jelas berbeda

\section{SIMPULAN}

Berdasarkan hasil penelitian tentangNovel Kartini Kisah Yang Tersembunyi karya Aguk Irawan MN analisis feminisme liberal dapat disimpulkan bahwa terdapat feminisme liberal yang mencakup data dari bentuk sosial, ekonomi, dan politik.

1. Feminisme liberal dalam aspek sosial terdapat beberapa data yang ditunjukkan pada novel Kartini Kisah yang Tersembunyi karya Aguk Irawan MN. salah satunya pada tokoh Ngasirah ibu Kartini. Ngasirah adalah anak dari Modirono seorang rakyat jelata yang bekerja sebagi buruh pabrik di Sosroningrat. Ngasirah di nikahi oleh Sosroningrat tetpai bukan jadi istri yang pertama melainkan menjadi istri selirdari seorang raja.

2. Aspek politik pada novel Kartini Kisah yang Tersembunyi karya Aguk Irawan MN. salah satunya pada tokoh Kartini yang ingin memberontak untuk pergi bersekolah ke Eropa, Batavia, dan Semarang agar bisa menjadi guru, dokter atau bidan supaya bisa mencerdaskan dan menyembuhkan orang yang sakit. Tetapi sampai Kartini umur 25 tahun dan menikah dan meninggal pada tahun itu juga, Kartini tetap tidak diperbolehkan karena itu sudah menjadi perjanjian di kerajaan kalau anak perempuan tidak diperbolehkan bersekolah seperti kakak laki-lakinya.

3. Aspek ekonomi pada novel Kartini Kisah yang Tersembunyi karya Aguk Irawan MN. salah satunya pada tokoh Kartini yang selalu direndahkan oleh Sulastri anak dari
RA Wuryam yang langsung dari kerajaan Madura sementara Kartini berasal dari Ngasirah yang bapaknya bernama Modirono yang langsung dari rakyat biasa tetapi di sebagai mandor di pabrik Sosroningrat dan anak Mbah Kaji yang terhormat di desanya.

\section{SARAN}

Berdasarkan simpulan dan mengacu pada manfaat penelitian maka disarankan sebagai berikut.

1. Penelitian ini diharapkan dapat bermanfaat bagi pengembangan ilmu sastra, khususnya analisis terhadap karya sastra novel yang di dalamnya memberikan kontribusi berbagai nilai yang bermanfaat bagi kehidupan manusia, khususnya dalam feminisme liberal.

2. Penelitian ini hanya terbatas mengenai feminisme liberal yang terdapat di dalam novel Kartini Kisah yang TersembunyiKarya Aguk Irawan MN. Oleh karena itu, perlu adanya penelitian selanjutnya terhadap novel yang menggunakan pendekatan atau sudut pandang yang lainnya. Selain itu dapat pula membahas aspek-aspek lain yang juga menarik untuk ditambahkan.

3. Hasil penelitian ini hendaknya dapat dijadikan salah satu acuan oleh pembaca untuk memahami kritik sosial dalam novel Kartini Kisah yang Tersembunyi karya Aguk Irawan MN. Disamping itu, pembaca juga hendaknya dapat memperoleh pengalaman dan wawasan tentang feminisme liberal. Selain itu, kisah tentang perjuangan tentang Kartini yang ingin menyetarakan hidupnya supaya tidak tertindas oleh kaum laki-laki. 
4. Masih banyak penelitian yang dapat dilakukan terhadap novel Kartini Kisah yang Tersembunyi karya Aguk Irawan MN dengan menggunakan pendekatan yang berebeda. Dengan demikian, masih terbuka luas bagi peneliti selanjutnya untuk melakukan penelitian dalam novel Kartini Kisah yang Tersembunyi karya Aguk Irawan MN dengan tindak lanjut penelitian ini.

\section{DAFTAR PUSTAKA}

Humm, Maggie.2002. Ensiklopedia Feminisme. Diterjemahkan oleh Mundi Rahayu. Yogyakarta: Fajar Pustaka Baru.

Irawan MN, Aguk.2016.Kartini Kisah Yang Tersembunyi. Tanggerang Selatan: JAVANICA PT Kaurama Buana Antara.

Kasir, Ibnu. 2016. Emansipasi Wanita dan Kesetaraan Gender dalam Pandangan
Islam.Tanggal 02 Juli 2017 pukul 15:20.

Khamdiyah, Heny.2016. Pemikiran Emansipasi Wanita dan Pendidikan R.A. Kartini, Buku Habis Gelap Terbitlah Terang, Tujuan Pendidikan Islam. Tanggal 10 Agustus 2017 pukul 21:05.

Moleong, Lexy. J. 2010. Metode PenelitianKualitatif. Remaja Rosdakarya. Bandung.

Rafiek. 2010. Pengkajian Sastra. Bandung: PT Refika Aditama.

Ratna Sari, Febria. 2012. Suara Marginal: Ideologi KepengangguranPerempuan. Tanggal 01 April 2017 pukul 17:00.

Sugihastuti dan itsna Hadi Setiawan. 2010. Gender dan Inferioritas Perempuan: Praktik Kritik Satra Feminis. Yogyakarta: Pustaka Pelajar. 